\title{
Investigation of the effect of carbon nanotubes on electrical properties of woven fiberglass/epoxy composite laminate
}

\author{
Elivazeta Kalugina ${ }^{1,2, *}$ \\ ${ }^{1}$ Novosibirsk State Technical University, 630087 Novosibirsk, Russia \\ ${ }^{2}$ OOO IK CTO, 630090 Novosibirsk, Russia
}

\begin{abstract}
The effect of epoxy modified by 0.05 wt. \% of CNTs on electrical properties of woven fiberglass/epoxy composite laminate was examined. The electrical resistance was measured using 4-point probe method and LCR-meter during cyclic tensile and fatigue test. Microstructural analysis using field emission scanning electron microscopy (FESEM) was carried out. Based on the experimental data, the increase in load is accompanied by growth in electrical resistance. The change in resistance after 20 cycles was up to $3 \%$. During fatigue test, the change in resistance was considerable and made up to $25 \%$ in cracking zone of the sample and over $110 \%$ at the failure mode.
\end{abstract}

\section{Introduction}

Glass fiber-reinforced polymer (GFRP) laminate has become a phenomenon being investigated extensively recently [1]. Carbon nanotubes (CNTs) addition to epoxy matrix up to $1 \mathrm{wt}$. \% leads to acquisition of electrical properties in the material and, in some cases, to additional mechanical improvement [2-4]. Small CNTs additive to epoxy matrix decreases electrical resistance of the material. CNTs additives can act as distributed sensors, which allow monitoring of the structural integrity and damage of such materials in industrial and civil applications [5, 6]. Nevertheless, CNTs are quite complex compounds and understanding on how various percentage concentration and type of CNTs affect electrical properties is still lacking [5]. Besides, unknown long-term behaviour of CNTs in the material causes a gap between results obtained in the laboratory and full-size applications.

The aim of the present paper is to investigate the effect of CNTs addition on electrical properties of woven fiberglass/epoxy composite laminate. This study is of great importance to determine the appropriate amount of CNTs in epoxy to get a well-defined correlation between load and resistance for structure monitoring systems.

\footnotetext{
* Corresponding author: cooingh9@gmail.com
} 


\section{Samples preparation}

Fiberglass/epoxy composite reinforced by CNTs was fabricated by combining hand lay-up and vacuum molding methods. Modified epoxy mixture was prepared by blending 0.05 wt. \% single-walled carbon nanotubes (SWCNTs) with epoxy resin. SWCNTs compound with TUBALL MATRIX 201 was manufactured by OCSiAl Ltd. In order to produce thorough dispersion, the mixture was mechanically stirred by stirring shaft for 40 minutes at $1500 \mathrm{rpm}$. Then epoxy-curing agent was added into the mixture. The mixture was stirred for 5 minutes and then exposed to outgassing process for 40 minutes. Outgassing vacuum pressure was 0.7 atm.

Fabricated sheets were covered by vacuum bag to pack down layers of woven fiberglass and epoxy. After that, the sheets were cured at room temperature for 24 hours and at $70{ }^{\circ} \mathrm{C}$ in vacuum oven for 8 hours. The specimens with dimensions $145 \times 30 \times 4.5 \mathrm{~mm}^{3}\left(\mathrm{~S}_{\mathrm{CS}}=135\right.$ $\mathrm{mm}^{2}$ ) were fabricated according to ASTM D 3039 Standard for tensile testing.

\section{Test setup}

Cyclic and fatigue tests were performed by means of Servo Hydraulic UNO Testing Machine (BiSS Ltd.). Specimens were mounted in the grips of the machine and loaded in tension while recording the force. To prevent gripping damage and electrically isolate the specimen from the testing machine tabs were used. A special cyclic test was carried out. The load was applied in steps of $5 \mathrm{kN}$ at a speed of testing $3 \mathrm{~mm} / \mathrm{min}$. It was increased to $20 \mathrm{kN}$ and then decreased to zero, resulting in 8 steps in total. This loading program was repeated 20 times. Load was maintained every $5 \mathrm{kN}$ for $10 \mathrm{~s}$ to fix and record the electrical resistance. Fatigue test was carried out at frequency of $2 \mathrm{~Hz}$ and cycle's stress of $\sigma_{\max }=$ $0.7 \sigma_{\text {UTS }}\left(\sigma_{\text {UTS }}=315.2 \mathrm{MPa}\right)$. During the fatigue test, there was the resistance measurement every 100 cycles until failure.

Electrical resistance measurements were carried out by utilizing 4-point method. The method is used in measurements of semiconductor material resistivity. The 4-point method proved to be more reliable and repeatable than measurement by using two electrodes [7].

4-point measurement scheme is shown on Figure 1.b. Four copper contacts were set on each sample symmetrically with an equal pitch of $20 \mathrm{~mm}$ and fixed with an electrically conductive adhesive to promote a larger contact area. Electrical insulation material was applied from above (Figure 1.a). The resistance was measured at an operating frequency of $1 \mathrm{kHz}$ and the voltage on the MCP BR2823 LCR-meter of $0.3 \mathrm{~V}$. Measurement accuracy of electrical resistance was $0.2 \%$.

Microstructural analysis was accomplished by means of field emission scanning electron microscopy (FESEM) using Carl Zeiss Merlin VP Compact.
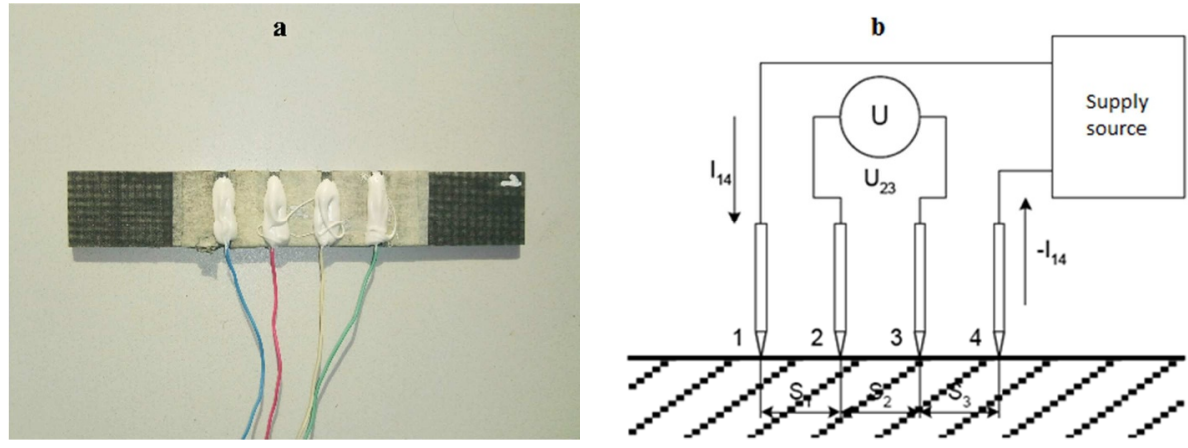

Fig. 1. a - electrical connection to LCR-meter. b - 4-point measurement scheme. 


\section{Results}

Figure 2 shows the SEM images of untested sample (a) and sample after fatigue test (b). Figure 2.a depicts the interfacial adhesion between epoxy matrix, longitudinal and transverse fibers. Figure 2.b shows the interfacial failure zone developed during fatigue test and accompanied by matrix cracking.
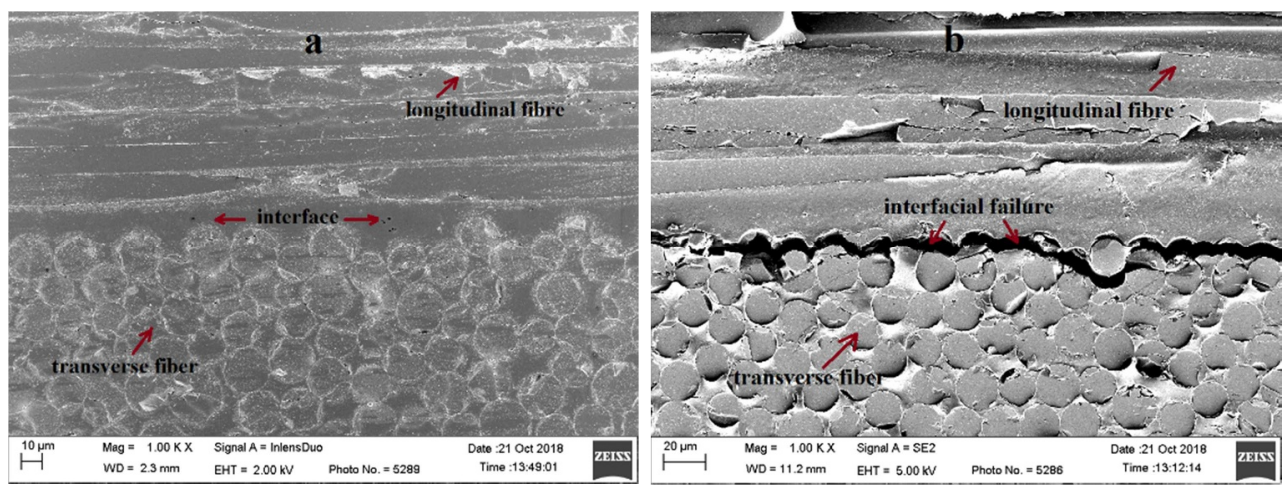

Fig. 2. $a$-untested sample. $b$ - sample after fatigue test.

Figure 3 shows high magnification images of the zone of epoxy crack in the fatiguetested sample. The red arrows mark long cylindrical objects of ca. $20 \mathrm{~nm}$ in diameter, possibly carbon nanotubes agglomerations.

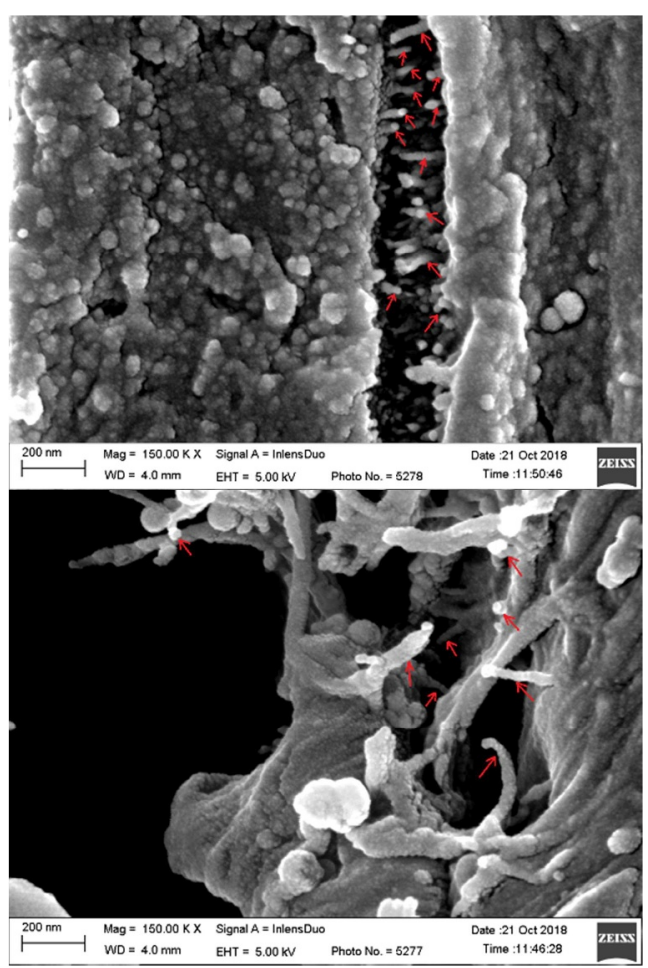

Fig. 3. SEM images of epoxy matrix crack in the fatigue-tested sample. 
During the cyclic test, the maximal load of $20 \mathrm{kN}(\approx 140 \mathrm{MPa})$ lies within elastic range of stress of the material obtained. Figure 4 shows the correlation between electrical resistance and load during the cyclic test. The curves presented on Figure 4 corresponds to the 1st and 20th cycles. Similar curves were obtained for all other cycles. Based on the correlation, it can be concluded that increasing applied load is provided with rise of electrical resistance. Thus, the tensile force action within the elastic range of stress up to $20 \mathrm{kN}$ probably causes structural changes in the sample of the material. It is remarkable that when the load is totally removed down to $0 \mathrm{kN}$, the electrical resistance value is almost returned to the value before loading. As a number of cycle goes up, the resistance corresponding to the load of $20 \mathrm{kN}$ is gradually growing from 12.6 to $13.09 \mathrm{k} \Omega$.

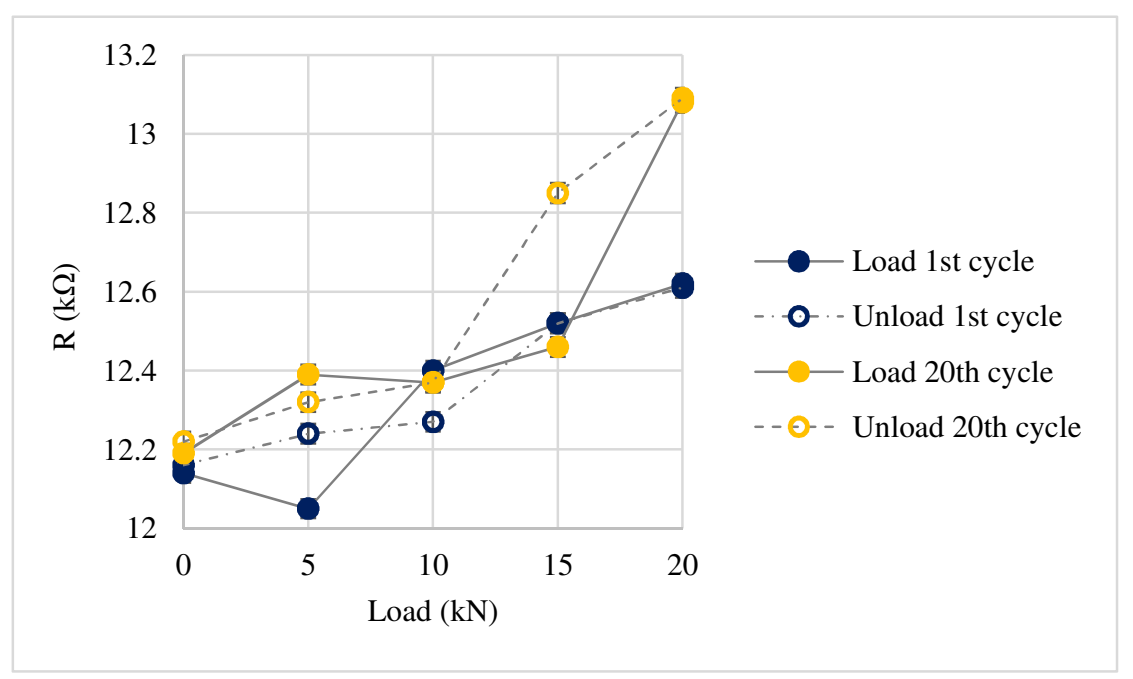

Fig. 4. Load and resistance correlation during cyclic tests.

Figure 5 shows fatigue test results. Until the 600th cycle, the resistance value remains steady within 13.7 and $14.1 \mathrm{k} \Omega$. Then it gradually increases from cycle 600 to 1800 . The increase in resistance is accompanied with sounds of composite cracking. The failure mode of the sample at 2000th cycle showed jump in resistance to $30 \mathrm{k} \Omega$. Changes in resistance were up to $25 \%$ in the cracking zone and over $110 \%$ at the failure mode.

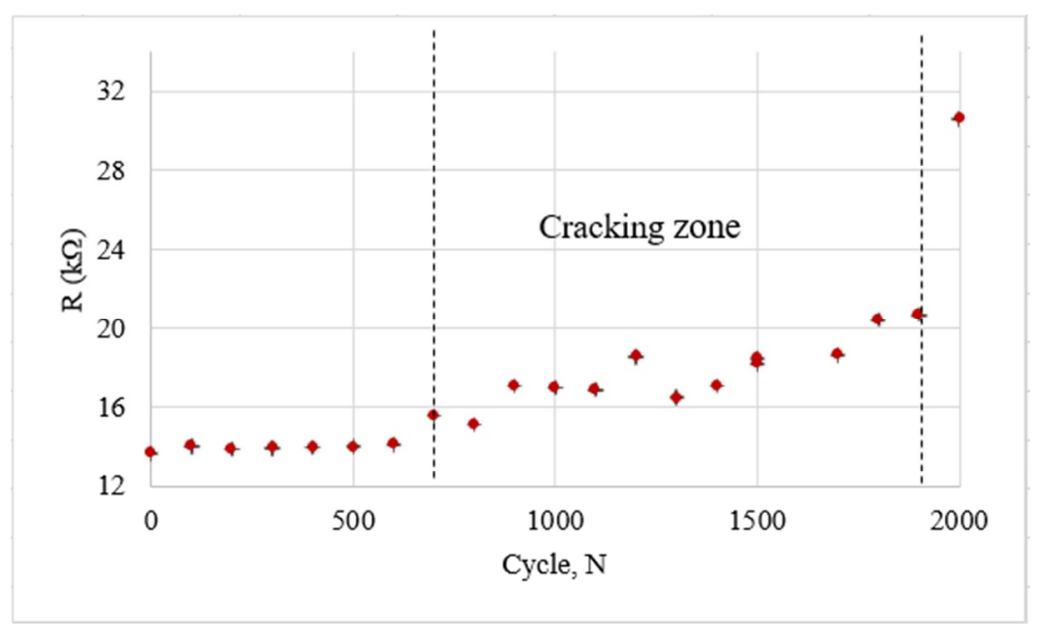

Fig. 5. Fatigue test results. 


\section{Conclusion}

The electrical properties of CNTs introduction to epoxy matrix was examined. The CNTs addition to epoxy up to $0.05 \mathrm{wt}$. \% provided polymer matrix with conductivity and damage detection using the resistance measurement.

Based on cyclic test data, an increase of applied load was provided with rise of electrical resistance. The resistance at the load of $20 \mathrm{kN}$ gradually grew till 20th and changed up to $3 \%$. Values of resistance practically return to the initial value before applying load. During fatigue test, the value of resistivity remains steady until cracking of the sample.

By means of FESEM analysis was established that interfacial failure due to matrix cracking causes destruction of SWCNTs conductive web. Apparently, this effect leads to growth in electrical resistance.

This work is supported by Foundation for Assistance to Small Innovative Enterprises (FASIE). "Start" program number is C1-32491.

\section{References}

1. T.P. Sathishkumar, J. Naveen, J. Reinf. Plast. Comp., 33(13), 1258-1275 (2014)

2. A. Allaoui, S. Bai, H.M. Cheng, J.B. Bai, Compos. Sci. Technol., 62 (2002)

3. J.N. Coleman, U. Khan, Y.K Gun'ko, Adv Mater., 18(6), 689-706 (2006)

4. H. Xiao, H. Li, G. Song, J. Polymer Compos., 36(9) 2014

5. H. Zhang, E. Bilotti, T. Peijs, Nanocomposites, 1(4), 167 (2016).

6. Y. Wang, R. Chang, G. Chen, Adv. Mech. Eng., 9, 2 (2017).

7. L. Arronche, V.L. Saponara, S. Yesil, G. Bayram, J. App. Polym., 3(5), 1-9 (2012) 